\title{
International week in Norwegian school. A qualitative study of the participant perspective
}

\author{
Joke Dewilde ${ }^{12}$, Ole Kolbjørn Kjørven², Anne Skaret² and Thor-André Skrefsrud² \\ 1 University of Oslo \\ ${ }^{2}$ Inland Norway University of Applied Science
}

\begin{abstract}
This article explores an international week in a Norwegian primary school from the perspective of the different participants in the arrangement. International week is typically organized in connection with the United Nation's day and is to contribute to the school's aim of inclusion and social justice. Whereas the research literature has been critical towards such weeks, using terms such as 'exotification' and 'hall-way multiculturalism', there has been scarce research on international weeks from the participants' perspectives. Our case study of a single international week is based on interviews with the school's management, and a selection of teachers, parents and students. The study both confirms and challenges the research literature's critical stance towards international week. Whereas these weeks may appear as 'happenings' communicating an essential view on cultures, they also show potential for critical reflection and for leaking into its surroundings, for example connecting school and the local community.
\end{abstract}

Keywords: international week, cultural identity, school celebration, multicultural education

\section{Introduction}

In this article, we report on a case study of an international week (IW) in a Norwegian primary school. IW is often seen as a contribution to the school's aim of inclusion and social justice and as a 'counter-discourse' to broader pedagogical discourses where the majority's language and culture dominate (cf. Cummins \& Early, 2011, p. 4). IW refers to a specific week, typically held in connection to the United Nations day ${ }^{1}$ October $24^{\text {th }}$, where the timetable is put aside and students are grouped across ages as they participate in a range of workshop-like activities to celebrate linguistic and cultural diversity. Many parties are involved, such as students, staff, parents and the local community. Typically, the week ends with school celebration and an exhibition of some kind, which includes posters of different countries, food dishes from across the world, and traditional costumes.

We set out to explore IW from the perspective of the different actors; the school management, teachers, students as well as parents. The background for our choice of starting point is to be found in prior research on the subject, which conveys a distinct and strong criticism of such arrangements, accusing them for being merely an appendix to the other activities of the school and for promoting stable understandings of students' cultural identity. However, this research has directed scarce attention to the participants' perspectives and the possible potential of these weeks (cf. National Centre for Multicultural Education, 2016a; 2016b). Thus, we set out to explore the following research question: What kind of meanings do

\footnotetext{
${ }^{1}$ United Nations Day (UND) marks the anniversary of the establishment of the United Nations in 1945 (United Nations, n.a.). UND is celebrated by many schools and is dedicated to the global efforts and achievements of the UN concerning international solidarity. In later years, however, UND is often incorporated in IW as a celebration of the schools' internal cultural, linguistic and religious diversity.
} 
the different participants ascribe to IW, and how can these be understood in view of the criticism in the research literature? In order to answer this question, we will first give an account for prior research and our theoretical lens, and thereafter present and discuss our analysis of the interview data in light of this.

\section{Prior research}

The research on the matter goes back about 30 years, reflecting the impact of multiculturalism on policy-making, which also encompassed the field of education (cf. Sleeter, 1991; Tiedt \& Tiedt, 1990). Although multicultural education research has been rich and diverse in this period of time (Banks \& Banks, 2004), the specific focus on IW and also other forms of school celebrations have been scarce, and at the same time, as mentioned in the introduction, consistently critical. In the following we will center the attention on two issues that dominate the research literature. The first concerns IW as a working method, and the second the concept of culture which underlies it.

Within the Norwegian context, Tove Skoug's (1989) report entitled To-kulturelt arbeid $i$ barnehagen [Bi-cultural work in kindergartens], represents the first study on the topic. Though placed in kindergartens, the principle discussion is transferable to schools. In her view, practices that are distinctively separated from the ordinary program, what she refers to as "special occasions", are counterproductive efforts of integration (p. 44). The reason is that these occasions, oftentimes named "theme events" and "parties", signify otherness, something distinctively "special" in relation to the normal program and also the "Norwegian norm" (p. 44).

Kamil Øzerk has a similar assessment, as he sees "special arrangements" as typical practices of "ethnification and festivalization", and also "appendixation" (Øzerk, 2008, p. 223). "Ethnification", then, as opposed to "normalization", "festivalization" as opposed to "academication", and "appendixation" as opposed to the practice of presenting cultural expressions not at "the end", but as a natural part of the "ordinary program" (Øzerk, 2008, p. 224). Again, "special arrangements" as a working method functions counterproductively, Øzerk claims, with respect to the schools' proclaimed aim of inclusion and social justice.

Of international research, we find Diane Hoffman's study of "multicultural education" in American schools representative of the critical position (Hoffmann, 1996). Reflecting on often-used activities during IW, she problematizes the practice of "hallway multiculturalism", that is, posters and decorations oftentimes made up by collages of "ethnic faces" and statements proclaiming "All Cultures are One" and "Diversity for Unity" (Hoffman, 1996, pp. 546-547). In Hoffman's view, what is being promoted is "ideological conformity", the notion that we should all "think in exactly the same way" (Hoffman, 1996, p. 547). The underlying idea in this is that all cultures are viewed as both fixed and equal, that they all represent the same and thus can be easily categorized and compared. This undermines, Hoffman argues, the experience of real cultural encounters, that is, "the reality of fuzzy borders and mutual interface and interdependency" of cultures (Hoffman, 1996, p. 550).

Hoffman concludes that IW manifests, and that more than any other practices in school, that "we really do not know how to 'do multiculturalism' in schools", and that, she continues, "despite the profusion of rhetoric that suggests the opposite" (Hoffman, 1996, p. 565). What is needed, according to Hoffman, is an approach that challenges "ideological conformity" and essentialist understandings of culture. In concrete terms that means to stimulate reflexivity, 
critical thinking, and self-awareness and by that create "opportunities for the kind of learning that leads to transformative understanding" (Hoffman, 1996, p. 550).

With the negative research literature as a backdrop, it is interesting to read Pia Niemi's (2016; 2014) recent PhD-study on Finnish students and teachers and their perceptions of traditional school celebrations such as Christmas and Independence Day. Despite pinpointing "the absence of interculturality in the celebrations", she underlines their positive effects on peer relations, school belonging and community building (Niemi \& Hotulainen, 2016, p. 12), and argues that they "encompass a potential for intercultural encounters" (Niemi et al., 2014, p. 262 264). Obviously, and as also our study shows, the participants bring in perspectives and arguments which indicate a larger complexity than the negative academic position has put forward.

\section{Theoretical perspectives on cultural identity}

More than ordinary school activities, IW allows the participants to engage in cultural and linguistic intermingling within the school context and thus acknowledge that language and cultural practices are an imbedded part of their identity. Accordingly, the concept of cultural identity becomes an important theoretical lens for our analysis and discussion of the data.

In recent years, the concept of cultural identity has been subjected to a comprehensively critical inquiry from a variety of disciplinary areas. The claim has been - in one way or another - to replace the conventional essentialist view of an integral and unified identity related to a specific geographic or ethnic community with a more dynamic concept (e.g. Bhabha, 2004; Meissner \& Vertovec, 2015; Sen, 2006; Welsch, 1999).

Wolfgang Welsch (1999, p. 205) argues for a shift in the understanding of cultural identity both at the micro and the macro level. At the micro level, the regular day-to-day interaction with others who matter to us means that the self is constantly formed and renewed in social processes of exchange and interrelations. The construction of identity at the micro level may be described like "a migration through different social worlds and as the successive realization of a number of possible identities" (Berger, Berger, \& Kellner, 1974, p. 77). Welsch thus draws on work from pioneers like George Herbert Mead (1934) and Anthony Giddens (1991) who both have underlined the relational aspects of identity formation. While Mead is best known for his work on the nature of the self and inter-subjectivity, Giddens draws attention to the self's capacity to integrate the response and reactions of others in the biographical narrative (1991, p. 54). To both Mead and Giddens, the ego is becoming aware of itself as it acts and thinks in social interaction with "significant others". The construction of the self is therefore not static, rather it is a psychological and social process that undergoes continuous change.

Also at the macro level, cultural identity is dynamic (Welsch, 1999, p. 197). The older concept of cultural identity has tried to separate cultures by using criteria like territory, customs and language. According to Welsch, however, cultures are always situated in social and historical processes of intercultural encounters. Shifting patterns of migration and processes of globalization bring cultures in contact with each other, making cultural communities entangled and highly complex (cf. Meissner \& Vertovec, 2015, p. 543). A growing diversification of cultural identity seems to be the norm as individuals are exposed to and may belong to a number of contexts simultaneously. Like Amartya Sen argues, the same person can be, without any 
contradiction, "an American citizen, of Caribbean origin, with African ancestry, a Christian, a liberal, a woman" (Sen, 2006, p. xii). Sometimes one membership category is significant for the individual's self-understanding, and sometimes another. What is needed, according to Sen, is a conception of cultural identity which recognizes that "each of these collectivities, to all of which this person simultaneously belongs, gives her a particular identity" (Sen, 2006, p. xii). At the same time, each of these collectivities is influenced by the other contexts as the ongoing constructive story about the self is an integrative process. Thus, both on the micro and the macro level, cultural identity is never stable, but always in flux.

From this theoretical position, we view IW as a cultural "contact zone", a term coined by Mary Louise Pratt, where "cultures meet, clash, and grapple with each other, often in contexts of highly asymmetrical relations of power" (Pratt, 1991, p. 34). With the intention of affirming the value of the minority cultures in the school community, questions like "who is in", "who is out" and "who decides" come to the foreground. Moreover, the notion of minority cultures signals the existence of a more powerful majority that has the resources to provide cultural encounters to take place. The majority has the power to define the "dominant system of classifications - in terms of religion, or community, or culture, or nation, or civilization" (Sen, 2006, p. xiii). From this perspective, IW is not a neutral celebration of diversity, but rather a space where differences come into play.

\section{The study}

The research project is designed as a qualitative study of a single case (Stake, 2010), bounded in time and place. Accordingly, we explored one IW at a large primary school in the East of Norway in the fall of 2015. Members of the research team have collaborated with the school in connection with previous research projects. This long-term relationship allowed us to hone in on this specific week and thus deepen our understanding of the school's pedagogical practice (cf. Madsen \& Karrebæk, 2015). The school has an inclusive multicultural profile, has a relatively long tradition for organizing this kind of weeks and is known for it in the municipality. The school also has a specific responsibility for the teaching of newly arrived students and for all bilingual teachers at primary school level in the municipality. This purposeful sample thus provides an information-rich case and gives us many opportunities for learning (cf. Patton, 1990).

The school's IW is always organized in connection with United Nation Day in October. Before the summer, a committee consisting of key teachers and a vice-principal starts the planning. In the course of the fall, more teachers and also parents are involved through the parent board. Some activities are the same from year to year such as students participating in a variety of workshops in across-age groups (e.g. Zumba dancing, lectures about countries, and singing songs from different countries) and the celebration of international day in the school's sports arena, where parents bring traditional dishes, countries are displayed on large posters, and students and parents engage in a performance. This year, the committee had decided to vow one day to the theme of multilingualism, and another day to the students and staff holding hands and making a physical chain around the school in order to confirm the school community.

We started our study by conducting a semi-structured interview with the school's management, consisting of a principal and two assisting principals (53 minutes), asking about why and how IW is important for the school, how the week has changed in the course of the 
years, examples of successful and unsuccessful events, organization, and their reflections on the representation of cultural identity in IW. Following from this, the team conducted fieldwork, using participant observation across the school during three days, writing in total 12000 words of field notes, taking 96 photographs of artefacts and students' work, and collecting documents such as the school's information leaflet and teaching materials especially designed for IW (cf. Brinkmann \& Kvale, 2015; Hammersley \& Atkinson, 2007).

In the course of the week, we also did semi-structured interviews with three teachers who functioned as key teachers in the planning committee (63 minutes). The interview questions were approximately the same as for the school's management, but now aiming at gaining an insight into IW from a teacher perspective. Furthermore, we also wanted to view IW from the parent perspective, as this school's IW relies heavily on efforts made by the parent group. The school's management assisted us in selecting parents who had been central in several IWs, and in particular the international days. We did a group interview with three parents (52 minutes), with backgrounds from Burma, Romania and Norway, respectively, and an individual interview with a parent with a Norwegian background who was the leader of the school's parent board during the first IW and one of the initiative takers (44 minutes).

To gain insight into IW from the perspective of the students, we decided to focus on the students from grade 6, as they have experienced several IWs previously and were available for interviews. We distributed a short open-ended questionnaire to the whole grade consisting of 56 students, and asked about what they particularly liked, and what they wished was different. Later, 22 of them gave their permission (as well as their parents or guardians) to be interviewed in pairs (140 minutes in total) with regard to the aforementioned questions.

For this article, we primarily draw on the interview data collected in the study since we take a particular interest in the perspective of the participants, as the qualitative interview is described as an appropriate methodological approach when studying the participant perspective focusing on meaning (Brinkmann \& Kvale, 2015; Fog, 2004; Spradley, 1979). All interviews were audio-recorded, transcribed verbatim and in extenso (129 pages). Our analyses were guided by abduction, which required us to search for codes and categories in our interview data, and see them in the light of previous theory (cf. Alvesson \& Sköldberg, 2009; Bruhn Jensen, 2012), thus constantly oscillating between the empirical data and the theoretical perspectives. First each member of the research team coded all interview statements. Then we met to discuss and agree upon the codes, before further categorizing the material. Three main categories emerged: 1) representations of culture and cultural identity, 2) IW as everyday- practice or as isolated event, and 3) the potential for reflection in IW, and they will be presented and analyzed in the following. In regard to the first category, we focus on the participants' reflections on representations of cultural elements in IW, in particular emphasizing the meanings ascribed to food and traditional meals. The second category concerns the participants' views on whether IW is an isolated event in the school year and to what degree it holds a potential to affect the school's every-day practices. Last, the third category regards the self-reflection and learning amongst the participants.

\section{Representations of culture and cultural identity in IW}

Cultural identity is a topical issue in IW at the school. In the interview with the school management, the principal explains how the whole celebration is founded on the nationalities, 
languages and minority cultures present in the student group at the school at the given time: "The home languages of the school are the starting point. It is the minority families who bring the food and who show their national costumes". This IW is thus characterized by a bottom-updesign, and hence an important goal is to affirm and recognize the students with minority backgrounds, making them proud of their backgrounds and heritages. The principal states that "it should confirm the identity of our students. And they are so wonderfully proud. That goes for the parents too, especially the mothers".

The mothers in the parent interview confirm the principal's statement. For instance, a mother with a Burmesian language background underscores the importance of highlighting traditions from the country of origin:

It is very important to us. We love our home country; our society and traditions. And we miss it while we live here. It means a lot to us to show it to other people.

Thus, it appears that from a minority perspective, the IW's focus on representation of minority cultures is perceived as a valuable and longed for opportunity to keep the memory and traditions from the country of origin alive. Furthermore, several students convey an equivalent view and point to the positive effects this IW design has on the students with minority backgrounds, as stated by an 11-year-old girl with Norwegian language background:

I think it was very good for the students who are from another country, when they show their outfits and stuff. They are completely different on stage and jump around like crazy, but once they are here [in the ordinary school setting], they are hiding and is really scared. So it was fun to see them jumping around and having fun, speaking their language.

Following from the bottom-up-design, the arrangement relies heavily on efforts made by parents with minority backgrounds, who bring traditional food dishes and dress up in traditional costumes from their countries and cultures of origin at the international day in the school's sports arena, as well as to holding several activities at the school during the week. Parents with minority backgrounds have managed activities such as hair braiding from Nigeria, folk tale traditions from Somalia, lectures about Romania, belly dance from Iran, and so on.

This way of celebrating minority cultures through the use of various cultural activities and artefacts is criticized by the research literature, as it could be said to promote an understanding of cultures and cultural identities as foreordained and stable entities. Aforementioned Sen (2006) and Homi K. Bhabha (2004) argue for viewing cultural identity as a fluent and dynamic process, which avoid stability and fixedness, and seen from this perspective, this school's IW seems to leave little room for an understanding of cultural identities as hybrid, being constantly negotiated and in change.

However, the participants do reflect more deeply on the matter than what the celebration may communicate at first sight. For instance, the key teachers have experienced incidents in previous IWs which have made them reflect upon the question of cultural identity with a more critical approach, and they do not hesitate to bring forth examples of their own unfortunate pedagogical choices

One incident the teachers reflected upon was at the festival in the school's sports arena where students with other mother tongues than Norwegian were expected to perform by speaking in those languages. However, some of them withdrew from the performance as they did not identify with the language that was assigned to them, a language they perceived it as 
their parents' language. This particular incident offered them a concrete example from which they could develop further insight into the complexity of culture, more specifically that cultural identity cannot be viewed as a ready-made box into which one can expect the students to fit into. Following from this and other trials and errors, the teachers reflect upon the importance of listening carefully to the students in such situations, approaching them with sensitivity and respect for the students' own opinions, as stated by one of the teachers:

Teacher 2: It's a challenge for us teachers to meet the parents in their desire to preserve their culture and their identity ... We have to keep in mind that we during an IW don't push some parents' homeland on the child who doesn't care about it.

This and other incidents demonstrate how the teachers reflect upon their prior IW experiences in order to enhance their future pedagogical practice, a point to which we will return to later in the article.

\section{Elements from the majority culture in IW}

Another question in regard to cultural identity that has received increased attention and awareness in this school's IW arrangements during the years is which role elements from the majority culture are set to play. Several participants commented that the majority culture was totally absent in the first years. The representative of the parent board formulates it like this: "The specific Norwegian was forgotten the first two years - and we really think it is equally important to lift forward Norwegian traditions as others - but it is more on track now". The vice-principal also refers to an incident two years ago when a mother dressed in Sami folk costume arrived at the festival with Sami food and the school realized that it had forgotten to set up a Sami table, thus showing that they also had overlooked a Norwegian indigenous culture in the arrangement.

In Skoug's (1989) aforementioned study on Vietnamese children in kindergartens in Norway, she finds that kindergartens who only highlight minority cultures on special occasions without treating the majority culture in the same explicit manner, run the risk of communicating that the latter is the natural and the norm, in opposition to the minority cultures, which are special and extraordinary (Skoug, 1989, p. 44). This criticism seems to strike this IW arrangement as it during the first years overlooked elements from the majority culture, forming certain understandings of IW amongst the participants. When students with Norwegian language background were asked in the interviews what they could do, many of them refused the idea of bringing food dishes or doing folk dances by saying for instance "no, I am completely Norwegian, so...", "if we were from another country we could have done it", and "if I was from another country I could probably make some food from that country, something traditional". Also the school management was aware of this:

\footnotetext{
Indeed, sometimes some of the children have said "oh, I wish I had a mom from another country". They felt so ordinary. Therefore, we had to emphasize Norwegian culture in all of this. We should also be proud of our own culture, right?
}

The key teachers commented on the absence of the majority culture in IW and how families with minority language backgrounds have made requests for "Norwegian culture" in connection to this celebration. But even if various reactions on the absence of majority culture elements have led to an enhanced focus on this matter in later celebrations, the key teachers find it hard 
to actively involve parents with majority language background, as it seems that they occupy a spectator's view on IW rather than seeing themselves as contributors. Teacher 1 reflects upon this matter in this way: "You become a little laidback, perhaps, and think that the week is international, not Norwegian". However, not all parents are reluctant, and the father with Norwegian language background states in the parent interview that he is willing to participate:

\footnotetext{
As an ethnic Norwegian parent I have not been involved, nor have I been asked to be involved. On the other hand, one year I showed up in my Norwegian bunad [folk costume]. I said that we have to show the Norwegian national costume too, so when I did it, others also did it. As a Norwegian parent I would indeed like to get more involved.
}

In this respect, different participants show a heightened level of consciousness in regard to the importance of highlighting traditions from all cultures at the school during IW, including elements of the majority culture, thus communicating that none of the cultures should be perceived as more "natural" or "normal" than the others.

\section{The meanings of food in IW}

A highlight in IW is the festival in the school's sports arena, which includes the serving of traditional food dishes, folk music, a catwalk with people showing their folk costumes as well as a performance. In all the interviews the participants comment upon the importance of food, showing that food is perceived to play a key role in the celebration. Food and the matter of sharing food, stand out as the most cherished activity, not least for the students, who comment that "the funniest thing is to taste the food from other countries" and "the food makes it all better". Also the parents mention the food as the high point, cheerfully describing how "the food and the cookies... it all disappears at once". It is typically the families with minority language backgrounds who bring traditional dishes from their countries of origin (the informants mention for instance spring rolls from Thailand, Swedish meatballs and samosa from Somalia), and in the last two years also traditional Norwegian food dishes have been served. The food is typically served from different tables by families often dressed in traditional folk costumes and accompanied by student-made posters conveying facts about the country of association. In this way people can move from "country to country", so to speak (a student refers in the interview to "when I was in Somalia", meaning when he visited the Somali table and ate samosa).

This way of representing cultures, easily falls under the criticism put forward by for instance Hoffman (1996) and her critique of cultural essentialism, as it promotes a view on cultures as something that holds a certain content, or essence, which can be collected and put on display. However, food in this IW seems to hold a multitude of meanings for the participants that reaches beyond cultural essentialism. The representative of the parent board highlight food as a purposeful stepping stone to talk and learn about cultures in interaction with other people: "we get to know the different cultures... and it is always nice to taste the food of others, but in a way it is of secondary importance". Viewing the tasting of food as secondary indicates that she views food as a means by which intercultural encounter are made possible. Food is not first and foremost important as such, but may open the possibility for cultural interrelation between the actors.

Furthermore, the representative of the parent board also says that the serving and tasting of food make the participants in IW move around and talk more easily to each other as food 
makes it "much easier to mingle". This implies that the food is viewed a well-functioning means which brings people together. But more than that, and as the principal emphasizes, the food constitutes a language in its own right, a "simple means of communicating ... a first step of introducing ... and showing who you are". In that respect, the vice-principal added, the conventional use of language, which for many represents a great barrier in communication, "is not so important". The following experience of the representative of the parent board illustrates this:

I think it's an easy way to learn about other cultures. At each table where the food is served, they have these big posters about the country, where it's located and so on. It's so accessible and available; the information almost seeps in without having to work for it. I didn't know for example, while waiting for the food I read that the Somali written language is only 40 years old. Only 40 years old! Well, that explains a few things.

As the example illustrates, the making of the food, serving it, and also the actual sharing and tasting-sequences has transformative potential. This is highlighted not least by sociological studies which state that a meal is a social event which forms certain social practices (see e.g. Holm, 2001; Mäkelä, 2009). Johanna Mäkelä (2009, p. 40) claims that food is "a marker of social relations" and that "a meal is essentially a social affair". Furthermore, Lotte Holm (2001, p. 159,160$)$ states that "[m]eals are media for bringing people together", and that "[m]eals unite, they assemble groups ... Thereby meals form basic occasions for groups to discover themselves as groups". In this view the communal sharing and eating of food in the festival can be said to have the function of uniting the participants and to build a community in which all participants play an important part.

Furthermore, the practices of serving and receiving food in IW may also be viewed in light of the metaphor of 'hospitality', which according to Mireille Rosello (2001) is an established metaphor in texts about a nation, typically called host, and its immigrants, typically referred to as guests. Rosello's point is that the relationship between host and guest should be viewed along a continuum which is in constant flux, and she also connects the metaphor to food and meals as she states the following: "Being at home is being where you can not only eat and drink but also invite someone to eat, to drink, to chat. Being at home is being where you can be the host, where you can offer hospitality" (Rosello, 2001, pp. 17-18). Following Rosello, the making and serving of food in this school's IW put the minority families in the host position, confirming their natural affiliation in the school community, whereas the participants with majority background get to take the guest position, thus temporarily turning the traditional power relations between majority and minority up-side-down. Obviously, there is more to food than simply confirming essentialist ethnic identity.

\section{IW as an isolated event or an every-day practice?}

As shown, Øzerk's (2008) notions of 'appendixication' and 'festivalization' aim at criticizing a practice where minority cultures are not included in the school's every-day life, but are only accentuated on special occasions as an isolated event beside the regular activity. Øzerk (2008, p. 223) further claims that this may lead to unfortunate results in regard to power relations in a society.

All in all the interview material shows a somewhat ambivalent understanding of the matter amongst the participants. On the one hand, several describe how IW stands out from the 
rest of the school year: As one of the parents states, it is in IW that the cultural diversity "blossoms" at the school, and the mother with Romanian language background comments that she would like her son to be able to present something from his country of origin during the entire school year and not only in IW. Also some of the students point out that the working methods during IW are different, as in more creative that they learn in different ways and work across the grades.

On the other hand, the participants also show how IW "leaks" in different ways and thus influences both the rest of the school year as well as the whole school community in different ways. The school's management point out how IW effects their general relationship with parents with minority backgrounds among them the Somali mothers, who they feel trust them more after several arrangements. Furthermore, the key teachers point out that they start planning the week three months in advance as well as sum it up afterwards, thus demonstrating that IW is in their consciousness for certain amount of time. The way that IW also dribbles into its surroundings and contributes to connect the school with its local community is also pinpointed by the school management as well as by the teachers:

Vice-principal: Last year a whole battalion suddenly attended at the end. I think there were twelve of them who came. We didn't know them, they had just heard about the arrangement. Not all of them had children at the school, but it doesn't seem to matter.

Teacher 1: I remember one Thursday afternoon, just before the International day. I came cycling and met fathers in flowing robes on their way to the school. It does something to the local community.

The former leader of the parent board also points out how IW has affected her social relationship with families from the minority cultures at the school:

For me, it's about being a part of the organizing committee which has brought me in contact with many immigrant parents. Some of them I have even come to know more personally.

Also the students comment on how the things they learn during IW also permeate ordinary practice and learning activities: "We learn a lot of things, and use it later also". In addition, the teachers point out that even though IW is mainly concentrated to one week during the school year, it has an important function in order to be a reminder on what they should do more often:

Teacher 3: It is about being reminded to do what we otherwise always should do... And I need that reminder every year with the IW, and I know that it lasts a little longer each year. So, it helps to have an IW several times.

Teacher 2: The most important with IW is to remind the staff of the responsibility that we say that we are taking. At least we take this responsibility this week, and it helps. And I think it has helped more in recent years. We can be more proud of the staff's approach to students who speak more than one language now, than we could ten years ago.

In sum, for the school's management and teachers IW provides certain experiences and insights into cultural diversity, which in turn seem to contribute to an awareness of cultural diversity and the variety of needs among the diverse student population. As we will show in the next section, these new insights seem to be fostered by an ongoing critical reflexivity by the staff.

\section{Reflexivity}

The school's management was well aware of the research field's negative position. The way they talked about the criticism revealed that they experienced the researchers' opinion about IWs - identified as "a hype" - somewhat condescending, and as just another example of the 
tension and dichotomy between academics and practitioners. We will argue that this awareness about the research field's position, points to a level of reflexivity about IW which certainly challenges Hoffmann's unflattering claim that "we really do not know how to 'do multiculturalism' in schools" (Hoffman, 1996, p. 565).

A first brief review of the data gives the impression that all the participants involved the school's management, the key teachers, parents and students - are unanimous in their positive assessment of the IW. This could move us towards confirming Hoffmann's conclusion, namely that the IW promoted the idea that "we should all think in exactly the same way" (Hoffman, 1996, p. 547). The participants, one could even argue, feel "exactly the same way", as the IW apparently represents a week full of joy and moments to remember. So when asked to come up with negative experiences, all the participants had difficulties recalling any at all. The ones that came up, and that only from the school's management and the key teachers involved, could hardly be characterized as severe incidents, more as events which put themselves in an embarrassing light (cf. the situation with the missing Sami table on p. 7).

This consistently positive attitude, however, should neither bring us towards the conclusion of uniformity, of "ideological conformity" (Hoffman, 1996, p. 547), nor of naiveté, shallowness, and that the participants, and then in particular the school's management and the key teachers in charge, were lacking self-awareness and critical sense. First of all, and what became obvious when we talked with all the participants, was that the positivity was genuine and strong-felt, leaving us with the general impression that the IW represented something of vital importance. Illustratively, when the students were confronted with the hypothetical question "What if the school decided to stop having IW?" many of them responded quickly and unanimously "No!" One of them, an 11-year-old student, said "then I would have protested!" confirming the image that came across in all the student interviews, that "I have never heard of anyone who does not want IW". The school's management, the key teachers and also the parents involved, summed up the importance of IW in similar ways, pointing to "its implications", as one parent put it, "for the whole school culture". The principal elaborated further on this by saying that "the IW is a symptom of what the school is all about", as it serves to establish" a common understanding of the school as a multicultural school. Students get to know each other across classes, groups and language. Something positive is happening. It makes us uplifted and happy!" Obviously, the joy and happiness, terms which were used several times by all the participants, were deep-felt, in many instances generated by transformative experiences.

Secondly, the overall positive assessments did not preclude self-criticism. To illustrate, one of the key teachers referred to an episode where they had used "the old poster of Syria" also referred to as "the Assad poster" obviously neglecting the changes due to the current disruptive times:

Teacher 2: We had the poster with Assad also last year, the same way we had the year before. And then things started to happen in Syria.

Teacher 3: Suddenly, he was not as popular anymore.

Teacher 2: And we got input from the parents so quickly, while we just thought the Syria poster looked neat.

Teacher 2: I would say I was a part of that. I approved the poster immediately! ... One has to be sharpened. From one year to the next it went from stability to a civil war, and we didn't think of that. It was quite embarrassing. 
In general terms, the school management referred to the first years as "amateurish", that "we started off with enthusiasm. That was the motivation". This self-knowledge indicates that the IW is not a static happening, but, and as the principal put it, has gone through "a great development". From the school management and key teachers' perspective, the "great development" applies to how the IW first was organized, as top-down, and where the school management was largely leaning on "a group with special competence", as the principal referred to the teachers working on the introductory program for newly arrived. This resulted, she admitted, in minimal involvement from the rest of the teacher staff, parents and also students. But gradually a broader basis of participation was built, until where it is now, reaching the level where even most of the parents, the parent board representative could tell, had a sense of "ownership to IW". The effect of this broader ownership is far-reaching. It has not only changed the IW, but also home-school relations. This can be illustrated with the principal's experience with "the Somali mothers":

We find that the Somali mothers trust us, they like us, hugging us when they meet us. Perhaps they would have done that anyway, but ... You notice that they trust you and that they feel they know us because they have been involved.

In this respect the IW represented a much needed arena, "an informal meeting-spot". And as such, the school management enthusiastically could tell, the IW did not only bring parents to the school, but triggered the participation of "fathers and brothers, aunts and uncles and children", even whole communities. So when reflecting on the impact of better parent and community involvement, the principal could not even envision the future of the IW. She said: "I don't know how it would look like in the future. There are new people, new generations and new things coming in". Still, the principal admitted, there is great potential for further improvements. To "utilize the parent group", recognized as a group with "lots of resources", the school needs to be more flexible and facilitate better for various contributions. She said: "We are so rigid and conventional and dependent on having an agenda and to stick to the system and the program". This, she continued, makes it difficult to welcome spontaneous inquiries such as "I would like to perform with you", meaning right now, because "it doesn't fit into the program". As one can see, the enthusiasm is colored by self-critical thoughts.

Concerning student involvement, all the participants had critical remarks. The students themselves requested "more activities" and "more things to do" when they were asked to say something about what they would see was different during the IW. In other words, they would not only be spectators but doers, in concrete terms that meant "to make the food", "to dance", "to do the handcrafts" etc. Although recognizing a development in more student involvement and that "the students look happy", the principal admitted that "we have never asked them about it", reflecting further on how the longtime tradition of strong teacher control on school arrangements still makes its mark. Occasionally, the parents too could remark, as one put it, that "there is a risk" that the "children come in the background". The critique, however, was not aimed at the teachers or the school management, but at themselves, thus confirming the decisive role the home cultures of the parents and families plays in this particular case.

To sum up, the level of reflexivity expressed in the interviews by all the participants, most importantly, by the key teachers and the school management as the ones in charge, 
challenges Hoffmann's view that "we really do not know how to 'do multiculturalism' in schools" (Hoffman, 1996, p. 565). Obviously, IW is regarded as a work in progress, as it has developed continuously based on the participants' enhanced awareness of what it means to be a diverse school. This, we will argue, could not have happened without a fundamentally open and self-critical attitude. Even though the staff is aware of IW's potential pitfalls, such as cultural essentialism, from their perspective IW creates a social space where voices from the margins become the center of attention, especially the parents', and thus provides further opportunities for building a more thorough inclusive platform (cf. Cummins \& Early, 2011).

\section{Conclusion}

The growing linguistic and cultural diversity in the Scandinavian countries and elsewhere, has led schools to organize school celebrations like IW in order to display and celebrate the variety of backgrounds and experiences among the students and the parents at the school. In this article, we set out to explore the different meanings various participants ascribe to an IW in a primary school in Norway. Our aim has been to understand more of how the experiences of the actors correspond with the critical claim from research literature that IW is an isolated event that overlooks the dynamic characteristics of cultural practices.

Our analysis shows that the participants both confirm and challenge the research literature's critical stance. While our findings recognize that IW may contribute to shape diversity by reinforcing linguistic and cultural borders, searching for a common platform from which to organize and understand cultures - which the critic from Hoffman and others emphasizes - the different actors involved also emphasize the positive potential of such a week.

The school's intention is that the IW should contribute to enhance participation and academic engagement and achievement for often marginalized students, as well as to articulate a 'counter-discourse' in a broader pedagogical perspective where majority's culture and language dominate (cf. Cummins \& Early, 2011, p. 4). In our study, the participants all report on a wide participation from different groups. In addition, the study shows that IW contributes to create spaces for communication and new understandings. Moreover, the analysis indicates that traditional hierarchies and power relations may be altered during the IW. The newcomers that often are seen as guests are now the hosts. Although the participants are encouraged to express, rather than to negotiate identities - which in itself is an expression of existing power relations - the dynamic and adaptive characteristics of cultural encounters makes IW into a powerful social space where constructions of new identities take place.

While IW may be criticized for delimiting the attention towards diversity to a single happening, the study indicates that in this case, knowledge, attitudes and skills leaks into everyday practice. From the perspective of the participants, the week seems to strengthen the schools' cooperation with the parents and to establish trustful relationships. Moreover, the comments from the key teachers and the school management about the "great development" of the IW over the years, underline that the week is more embedded in ordinary pedagogical reflection and practice than the critic may insinuate. Thus, the findings in our case study indicate a larger complexity with regard to the function and effects of an IW than earlier research suggests.

In her study on school celebrations in Finnish schools, Niemi pointed to their important, but unexplored, pedagogical potential (Niemi \& Hotulainen, 2016; Niemi et al., 2014). Our study on IW shows how school celebrations with a particular focus on minorities appear as alternative spaces where voices from the margins flourish in negotiation with the greater (school) community. Extended research is needed on factual negotiations between the different 
actors, for example between parents, and between parents and children, and the meaning of these arrangements for the relationship between the school and the larger community. Moreover, in our study a cultural element like traditional food is important to the participants. Thus, we need more research on the meaning the participants ascribe to such a cultural element and how it may affect the intercultural encounter. In addition, extended research is needed on what cultural artefacts that are left out in school celebrations, and for what reasons. More casestudies like the one presented in this article are needed in order to gain more insight into IW as an inclusive way for schools to celebrate a growing diversity.

\section{Reference list}

Alvesson, Mats, \& Sköldberg, Kaj. (2009). Reflexive methodology: New vistas for qualitative research (2nd ed.). London: Sage.

Banks, James A., \& Banks, Cherry A. McGee. (2004). Handbook of research on multicultural education (2nd ed. ed.). San Francisco: Jossey-Bass.

Berger, Peter L., Berger, Brigitte, \& Kellner, Hansfried. (1974). The homeless mind: Modernization and consciousness. New York: Random House.

Bhabha, Homi K. (2004). The location of culture. London: Routledge.

Brinkmann, Svend, \& Kvale, Steinar. (2015). InterViews: Learning the craft of qualitative research interviewing (3rd ed.). Thousand Oaks, California: Sage.

Bruhn Jensen, Klaus. (2012). The complementarity of qualitative and quantitative methodologies in media and communication research. In K. Bruhn Jensen (Ed.), A Handbook of media and communication research: Qualitative and quantitative methodologies (2nd ed., pp. 283-301). London: Routledge.

Cummins, Jim, \& Early, Margaret. (2011). Introduction. In J. Cummins \& M. Early (Eds.), Identity texts: The collaborative creation of power in multilingual schools (pp. 3-19). London: Trentham Books.

Fog, Jette. (2004). Med samtalen som udgangspunkt: Det kvalitative forskningsinterview [The conversation as a starting point: The qualitative research interview] (2nd ed.). København: Akademisk Forlag.

Giddens, Anthony. (1991). Modernity and self-identity: Self and society in the late modern age. Cambridge: Polity Press.

Hammersley, Martyn, \& Atkinson, Paul. (2007). Ethnography: Principles in practice (3rd ed.). London: Routledge.

Hoffman, Diane M. (1996). Culture and Self in Multicultural Education: Reflections on Discourse, Text, and Practice. American Educational Research Journal, 33(3), 545-569.

Holm, Lotte. (2001). The social context of eating. In U. Kjærnes (Ed.), Eating patterns: A day in the lives of Nordic people (Vol. 7, pp. 159-198). Lysaker: National Instititute for Consumer Research.

Madsen, Lian Malai, \& Karrebæk, Martha Sif. (2015). Hip hop, education and poycentricity. In J. Snell, S. Shaw \& F. Copland (Eds.), Linguistic ethnography: Interdisciplinary explorations (pp. 246265): Palgrave Macmillan.

Mead, George Herbert. (1934). Mind, self, and society: From the standpoint of a social behaviorist (Vol. 1). Chicago: University of Chicago Press.

Meissner, Fran, \& Vertovec, Steven. (2015). Comparing super-diversity. Ethnic and Racial Studies, 38(4), 541-555. doi: 10.1080/01419870.2015.980295

Mäkelä, Johanna. (2009). Meals: The social perspective. In H. L. Meiselman (Ed.), Meals in Science and Practice. Interdisciplinary research and business applications (pp. 37-49). Oxford: Woodhouse Publishing Limited/Elsevier.

National Centre for Multicultural Education. (2016a). Fagerlund skole, Ringsaker. from http://nafo.hioa.no/grunnskole/nettverk/fokusvirksomheter/fagerlund-skole-ringsaker/ 
National Centre for Multicultural Education. (2016b). Prestrud skole, Hamar. from http://nafo.hioa.no/grunnskole/nettverk/fokusvirksomheter/prestrud-skole-hamar/

Niemi, Pia-Maria, \& Hotulainen, Risto. (2016). Enhancing students' sense of belonging through school celebrations: A study in Finnish lower-secondary schools. International Journal of Research Studies in Education, 5(2). doi: 10.5861/ijrse.2015.1197

Niemi, Pia-Maria, Kuusisto, Arniika, \& Kallioniemi, Arto. (2014). Discussing school celebrations from an intercultural perspective - a study in the Finnish context. Intercultural Education, 25(4), 255-268. doi: 10.1080/14675986.2014.926143

Patton, Michael Quinn. (1990). Qualitative evaluation and research methods (2nd ed.). Newbury Park: Sage.

Pratt, Mary Louise. (1991). Arts of the contact zone. Profession, 91, 33-40.

Rosello, Mireille. (2001). Postcolonial hospitality. The immigrant as guest. California: Stanford University Press.

Sen, Amartya. (2006). Identity and violence: The illusion of destiny. New York: Norton.

Skoug, Tove. (1989). To-kulturelt arbeide i barnehagen [Bi-cultural work in kindergarden) Vallset: Oplandske Bokforlag.

Sleeter, Christine E. (1991). Empowerment through Multicultural Education.

Spradley, James P. (1979). The ethnographic interview. New York: Holt, Rinehart \& Winston.

Stake, Robert E. (2010). Qualitative research: Studying how things work. New York: Guilford.

Tiedt, Pamela L., \& Tiedt, Iris M. (1990). Multicultural teaching: a handbook of activities, information, and resources. Boston: Allyn and Bacon.

United Nations. (n.a.). United Nations Day 24 October. Retrieved 20.05, 2016, from http://www.un.org/en/events/unday/

Welsch, Wolfgang. (1999). Transculturality: The puzzling form of cultures today. In M. Featherstone \& S. Lash (Eds.), Spaces of Culture. City, Nation, World (pp. 194-213). London: Sage Publications.

Øzerk, Kamil. (2008). Interkulturell danning i en flerkulturell skole: Dens vilkår, forutsetninger og funksjoner [Intercultural Bildung in a multicultural school: Its conditions, requirements and functions]. In P. Arneberg \& L. G. Briseid (Eds.), Fag og danning: Mellom individ og fellesskap (pp. 209-228). Bergen: Fagbokforlaget. 